'My Journey Map': Developing a qualitative approach to mapping young people's progress in residential rehabilitation

\title{
Lynn Roarty ${ }^{1}$, Helen Wildy ${ }^{2}$, Sherry Saggers ${ }^{1}$, Katherine Conigrave $^{3}$, Mandy Wilson $^{1}$, Kathryn Di Nicola ${ }^{4}$, Jody Webb ${ }^{5}$, Joanne Faulkner ${ }^{2}$
}

June 2012

\footnotetext{
${ }^{1}$ National Drug Research Institute, Curtin University

${ }^{2}$ The University of Western Australia

${ }^{3}$ Royal Prince Alfred Hospital and Sydney Medical School, the University of Sydney

${ }^{4}$ Department of Families, Housing, Community Services and Indigenous Affairs, formerly Mission Australia

${ }^{5}$ NSW Police Force, formerly Mission Australia
}

Corresponding author:

Dr Lynn Roarty

National Drug Research Institute

Curtin University

GPO Box U1987

Perth WA 6845

Email: I.roarty@curtin.edu.au

Phone: 0892661614 


\section{Biographical information}

Lynn Roarty is a Research Fellow in the Prevention, Early Intervention and Inequality program at the National Drug Research Institute, Curtin University.

Helen Wildy is Winthrop Professor and Dean of the Faculty of Education at The University of Western Australia.

Sherry Saggers was formerly Professor and Project Leader of the Prevention, Early Intervention and Inequality program at the National Drug Research Institute, Curtin University and is now Adjunct Professor at the National Drug Research Institute, Curtin University.

Katherine Conigrave is Senior Staff Specialist and Professor, Addiction Medicine, Royal Prince Alfred Hospital and Sydney Medical School , the University of Sydney

Mandy Wilson is a Research Fellow in the Substance Use Among Indigenous Australians program at the National Drug Research Institute, Curtin University.

Kathryn Di Nicola was formerly Senior Research \& Projects Officer with Mission Australia, and is now Assistant Section Manager, Homelessness Policy Section, with the Department of Families, Housing, Community Services and Indigenous Affairs.

Jody Webb was formerly Project Officer: Assessment, Research \& Development with Mission Australia, and is now Project Officer: Performance Improvement \& Planning Command with the NSW Police Force.

Joanne Faulkner was formerly a Research Officer in the Graduate School of Education, and is now Senior Project Officer, Student Services, at The University of Western Australia. 
'My Journey Map': Developing a qualitative approach to mapping young people's progress in residential rehabilitation 


\section{Abstract}

Young people with substance misuse issues are at risk of harm from significant negative health and life events. Contemporary research notes both an historical failure to recognise the unique needs of adolescents, and the ongoing need for dedicated adolescent treatment programs and outcome measures. It is concerning that there is so little literature assessing the quality, availability, and effectiveness of adolescent-focussed treatment programs, and no adolescent-specific measurement tools centred on a young person's progress in residential treatment.

This paper reports on the process of developing a qualitative approach to mapping progress in treatment over time. The research seeks to develop an approach that captures, at three points in time and from multiple viewpoints, the progress of young people in four residential rehabilitation services located in New South Wales and Western Australia, across several dimensions of the personal and social aspects of life. Our aim is to develop an approach that is accessible to the alcohol and other drug (AOD) workforce, and that informs the development of a psychometrically robust quantitative measure of progress that is meaningful and useful both to practitioners and to the young people themselves. 


\section{Introduction}

The risk of harm to young people who misuse psychoactive substances is well recognised (Bukstein \& Winters, 2004; Delaney, Broome, Flynn, \& Fletcher, 2001; Fletcher, Calafat, Pirona, \& Olszewski, 2010; Loxley, Toumbourou, \& Stockwell, 2004). These young people are more likely to face significant negative health and life events such as depression and anxiety, post-traumatic stress disorder (PTSD), violence (including sex-related violence) and trauma, suicidal ideation, difficulties with schooling, and family dysfunction (Ford II et al., 2007; Joshi, Grella, \& Hser, 2001; Prior, Sanson, Smart, \& Oberklaid, 2000; Staiger, Melville, Hides, Kambouropoulos, \& Lubman, 2009). They are also less likely to obtain or retain stable employment(Gray \& Saggers, 2005; Wilson, Saggers, \& Wildy, 2008). As well as personal costs, their substance misuse results in economic and social costs (Australian Institute of Health and Welfare, 2005; Chassin, Knight, Vargas-Chanes, Losoya, \& Naranjo, 2009; Collins \& Lapsley, 2002; Rounds-Bryant, Kristiansen, Fairbank, \& Hubbard, 1998), and also represents the potential loss to society of the unique contributions of these young people.

It is of concern, then, that there is little literature assessing the quality, availability, and effectiveness of adolescent-focussed treatment programs (American Association of Children's Residential Centers, 2009; Knudsen, 2009; Wagner, 2009). The results from outcome studies for young people in residential rehabilitation for drug and alcohol issues are equivocal, but, on the other hand, available measures of outcome success are limited. The most frequently used indicators for measuring success in treatment are retention, completion, and post-treatment abstinence (K. Winters, Stinchfield, Latimer, \& Lee, 2007). While duration in treatment is acknowledged to contribute to more positive outcomes (Chung \& Maisto, 2009) and, for all age groups, any time in treatment is better than none at all (Toumbourou, Hamilton, \& Fallon, 1998), research shows that retention of young people in treatment is both hard to achieve and hard to use as a progress measure. Retention, and thus completion, is influenced by a number of factors that include motivation, compulsory retention in treatment (via, for example, the juvenile justice system), and family and geographic 
barriers (Colby, Lee, Lewis-Esquerre, Esposito-Smythers, \& Monti, 2004). At-risk adolescents in particular are less likely to complete treatment, but the clinical experience can nonetheless be valuable for them (Faw, Hogue, \& Liddle, 2005). Some research suggests that progress made within treatment may be more predictive of positive outcomes than retention alone (Toumbourou et al., 1998), and this may especially be the case with young people (Williams \& Chang, 2000).

There are numerous tools available for measuring factors relevant to problematic substance use. In his review of "the most relevant and useful" domestic and international tools in the drug and alcohol sector (Deady, 2009, p. 8), Deady organises 119 standardised screening, assessment and outcome tools into eight categories of global measures. These are: general health and functioning; general mental health; specific mental health; positive mental health; general substance misuse; severity of substance misuse, and craving measures (Deady, 2009, p. 12). While few of these measures are child or adolescent-specific, some have been adapted or used with varying success with these cohorts. However, many of these tools require training to administer, and are time intensive in administration and scoring time (Deady, 2009), factors which potentially alienate young people and limit their use by time-poor practitioners (Brown, 2004, p. 39). None of them focus on progress in residential treatment - in particular, growth in insight.

Contemporary research notes both an historical failure to recognise the unique needs of adolescents (Etheridge, Smith, Rounds-Bryant, \& Hubbard, 2001; Flanzer, 2005; Hser et al., 2001), and the ongoing need for dedicated adolescent treatment programs and outcome measures (Hser et al., 2001; Marsden et al., 1998; SAMHSA, 2004; Szirom, King, \& Desmond, 2004; K. C. Winters, 1992). In recent research, Wagner (2008) states that although there is an acknowledged need, "scant information exists about developmentally informed approaches to treatment research with alcohol abusing teens" (p. S337). 
Butler and colleagues (2009) assert that outcome studies of adolescent residential programs suffer from a range of additional problems. As well as methodological variation, they cite a number of systemic barriers to quality data collection, including caseload size, and staff time and resources available to cooperate in or conduct data collection (p. 75). Boyd and colleagues (2007) also observe that staff "often view 'research' as a series of meaningless activities that interfere with regular, required clinical and administrative duties" (pp. 45-46).

As a result of these difficulties, Butler and colleagues (2009) conclude that useful measured outcomes are most often those that occur 'naturally' (p. 77). Bell (2007) argues, similarly, that most research on service design and delivery in adolescent alcohol and other drug rehabilitation settings has a "focus on isolated variables and large datasets [that] may not help the service professional" ( $p$. 107). She suggests that outcomes research needs instead to work qualitatively to help staff deal with the multi-dimensional, multi-layered, non-linear, variable and diverse nature of the service and the clients it serves.

A "stages of change" model, similar to that developed within Prochaska \& DiClemente's Transtheoretical Model (Prochaska, DiClemente, \& Norcross, 1992), lends itself well to a qualitative approach to tracking behaviour change in research. It also can help clinicians to tailor their interventions as young people progress through treatment. While change occurs from Precontemplation (lack of intention to change), through a series of discrete stages to Maintenance (sustained change), the process itself is an iterative one, allowing for regression back to previous stages at times throughout the process. This study draws upon this theoretical framework, and on preliminary research in two residential rehabilitation services observing the language and other behaviours of the young people (Wilson et al., 2008), in the development of a qualitative approach to mapping progress in treatment over time. 


\section{The background to this project}

The current project builds upon a collaborative preliminary qualitative study conducted in two drug and alcohol services for young people in Perth, Western Australia in 2007-2008 (Wilson et al., 2008). This earlier study developed a composite profile of the progress of the young people in treatment for alcohol and other drug (AOD) issues through a cross-sectional qualitative study. A participatory action research approach was used to enable the researchers and service practitioners to work collaboratively. Through analysis of documentary material gathered from the services, participant observation, and interviews with young people, staff, and families, a framework was constructed to describe young people's progress through treatment. This, in particular, drew on young people's stories of their experiences and progress, and on the reports and descriptions of staff. The framework consisted of a continuum of five stages: stage one - removed from 'being normal'; stage two - resisting treatment; stage three - reflecting on the journey; stage four - imagining a future; and stage five - 'being normal'. The stages were further described through a set of six dimensions reflecting the varied elements that interact and impact on the young people's lives: social location, emotional and psychological states, physical condition, drug use, high risk behaviour, and developmental issues.

Having developed the framework in the preliminary research, the next step was to use this to inform the design of a developmentally informed, qualitative approach for use by clinicians. Our approach incorporates the insights of the young people into fictional narratives reflecting each of the framework's five stages, and uses the responses of the young people in residential rehabilitation settings to these narratives to generate quantitative data, enabling the approach to be used in scoring or ranking a young person's progress through treatment.

\section{Aims of the project}


This paper reports on the process of developing a qualitative approach to mapping progress in treatment over time. Our aim is to develop an approach that is accessible to the alcohol and other drug (AOD) workforce, and that can inform the development of a psychometrically robust quantitative measure of progress that is meaningful and useful both to practitioners and to the young people themselves.

The specific aims of the current research are to:

- establish the validity of a qualitative framework to assess the progress of young people in residential treatment;

- develop an assessment approach for practical implementation based on the framework;

- check the psychometric properties of the assessment approach; and

- investigate the applicability of the framework and the approach in a range of residential rehabilitation settings.

This paper focuses on the processes involved in achieving the first two of these research aims.

\section{Ethical approach}

The project has been approved by Human Research Ethics Committees of Curtin University, Western Australia (HR06/2010), and The University of Western Australia (RA/4/1/4211). In addition, an ethics application was required and approved by the internal ethics committee of one of the participating service providers. The research was carried out according to the guidelines for conducting research involving young people outlined in the Australian National Health and Medical Research Council's National Statement on Ethical Conduct in Research Involving Humans and guidelines for conducting research with people in dependent or unequal relationships (National Health and Medical Research Council, 2007).

\section{Method}


The current project involves a multidisciplinary research team of social scientists, educators, psychologists, clinicians, addiction specialists, alcohol and other drug services staff, and government policy makers. An Instrument Development Group (IDG) was formed within the larger research team to develop the assessment approach. Monthly teleconferences were held between February and August 2010, supplemented by a team workshop held in Sydney in September 2010 and irregular small group meetings held in Perth in the latter months of the year.

\section{Developing an approach for rating progress}

We wanted to design an approach that would reflect and contextualise an integrated view of the complexity and 'messiness' of life across a number of domains, rather than fragment the life of the young person into isolated items scored separately and given equal weight. Initial development of the approach involved an iterative process. One of us (Wilson) wrote thematic 'sets' of narratives reflecting each of the stages of progress in the framework. We based these around a particular experience familiar to the young people from their stay in the service, for example around an excursion 'at the beach' or 'going shopping'. The language of the narratives reflected, as closely as possible, the vernacular of the young people themselves as observed during participant observation and interviews in the earlier research. Other members of the IDG then attempted to determine which 'stage' each of the five narratives depicted and, where there was lack of clarity, the elements of the narratives were discussed and refined. Once the IDG had settled on four thematic 'sets' of narratives that appeared accurately to reflect the five stages, these were tested across the larger team, in focus groups with young people and practitioners, and at a workshop held with the service practitioners. As well as consolidating the face validity of the framework of stages, the aim of the workshop was to establish the key requirements of the approach for mapping outcomes of treatment in a real life treatment setting.

\section{Results of the workshop}


It was agreed that the sixth outcome dimension (high risk behaviour) included within the global stages delineated in the original research should be removed, with workshop participants noting that each of the other five stages would incorporate elements of risky behaviour. The agreed upon global stages then were: social; emotional and psychological; physical; drug use, and developmental. Through a process of discussion and consolidation, each dimension was then further broken down into a series of aspects - for example, the social dimension contains four aspects: family, peers, partner, and society (Table 1). 
Table 1: Aspects of dimensions

\begin{tabular}{|l|l|l|l|l|}
\hline $\begin{array}{l}\text { Aspects of the } \\
\text { Social } \\
\text { dimension }\end{array}$ & $\begin{array}{l}\text { Aspects of the } \\
\text { Emotional and } \\
\text { Psychological } \\
\text { dimension }\end{array}$ & $\begin{array}{l}\text { Aspects of the } \\
\text { Physical } \\
\text { dimension }\end{array}$ & $\begin{array}{l}\text { Aspects of the } \\
\text { Drug Use } \\
\text { dimension }\end{array}$ & $\begin{array}{l}\text { Aspects of the } \\
\text { Developmental } \\
\text { dimension }\end{array}$ \\
\hline $\begin{array}{l}\text { family } \\
\text { peers } \\
\text { partner }\end{array}$ & $\begin{array}{l}\text { self } \\
\text { mood }\end{array}$ & $\begin{array}{l}\text { nutrition } \\
\text { body } \\
\text { sexual health }\end{array}$ & $\begin{array}{l}\text { goals } \\
\text { thoughts } \\
\text { knowledge }\end{array}$ & $\begin{array}{l}\text { responsibility } \\
\text { independence }\end{array}$ \\
\hline
\end{tabular}


'Sets' of narratives around each aspect of the five dimensions, situated within each of the global stages and incorporating the insights of workshop participants, were then written collaboratively by five members of the team (Wilson, Wildy, Saggers, Roarty \& Faulkner). Outcomes from discussions by workshop participants were also drawn upon in deciding on the demographic and other elements to be incorporated into the draft design, including the artwork and colour which were expected to distinguish the MJM from other outcome assessment tools in use, and to make it more appealing to young people. Both a draft paper-based approach called My Journey Map (MJM) and an e-version (eMJM) were produced and released to team members for testing and comment.

\section{Establishing the validity of the framework}

The face validity of the framework of five global stages enunciated in the foundation research was examined through four focus groups conducted in August 2010 separately with staff and young people in two services in New South Wales. Participants were shown the outline and description of the stages (Table 2) and then asked to order sets of narratives around a specific theme from stages one to five. 
Table 2: Description of stages

\begin{tabular}{|l|l|l|l|l|}
\hline $\begin{array}{l}\text { Global } \\
\text { Stage One }\end{array}$ & $\begin{array}{l}\text { Global } \\
\text { Stage Two }\end{array}$ & $\begin{array}{l}\text { Global } \\
\text { Stage Three }\end{array}$ & $\begin{array}{l}\text { Global } \\
\text { Stage Four }\end{array}$ & $\begin{array}{l}\text { Global } \\
\text { Stage Five }\end{array}$ \\
\hline Shut down & Resisting & Awakening & Dreaming & Doing \\
\hline $\begin{array}{l}\text { Removed from } \\
\text { 'being normal' }\end{array}$ & $\begin{array}{l}\text { Resisting } \\
\text { boundaries }\end{array}$ & $\begin{array}{l}\text { Reflecting on } \\
\text { journey }\end{array}$ & $\begin{array}{l}\text { Imagining a } \\
\text { future }\end{array}$ & Being 'normal' \\
\hline $\begin{array}{l}\text { Unwell } \\
\text { Lack of care for } \\
\text { self }\end{array}$ & Breaking rules & $\begin{array}{l}\text { Head clearing } \\
\text { Weight change } \\
\text { Potentially } \\
\text { explosive }\end{array}$ & $\begin{array}{l}\text { Eating healthily } \\
\text { Getting fit } \\
\text { Meginning to } \\
\text { care for self } \\
\text { to self- } \\
\text { presentation } \\
\text { offensiven languagen }\end{array}$ & $\begin{array}{l}\text { Enjoying being well } \\
\text { Forward-looking }\end{array}$ \\
\hline
\end{tabular}


The stage one narrative for the 'set' titled 'The Outing', for example, was:

I only came to this fucking place yesterday and I'm on a fucking bus. There's so much noise. My head hurts. Who are these idiots fighting over the fucking radio? What I am doing here? And where the fuck are we going on this goddamn bus? I don't give a shit; we could be going to the moon and I'd still hate it. As soon as this bus stops I'm fucking out of here.

And the stage three narrative in the same thematic set read:

We're on the weekly outing. This time it's the beach. Can't remember the last time I felt the sun on my skin; it feels real good. There're so many people here. This is what fucking normal people do! We missed an outing last week because Jeremy brought in drugs. Shit hit the fan. I didn't take any, but it made me really hang. Gary [staff member] congratulated me for being strong.

The young people enjoyed the process of reading and ordering the narratives, had little difficulty in assigning them to the correct stage, and many of the young people volunteered ideas and personal stories around which we could base further narrative sets. One of the focus group facilitators (Wildy) commented that "the young people were, without fail ... deeply interested". Staff members spontaneously commented that the narratives seemed very real to them, indicating that they accurately reflected the changes to the activities, language, behaviours and attitudes of their clients as they progressed through the five stages - resistant behaviours and intentionally offensive language in the early 'shut down' and 'resisting' stages gradually moving towards the more cooperative and socially acceptable attitudes and language that are characteristic of the later stages in the framework. One staff member asked "Have you been following me around?", and another was convinced that a particular set of narratives had been developed based on her service, as one of the stories exactly reflected something that had happened to her. 
Minor changes were made to some of the narratives following feedback from the focus groups. In particular, references to 'hunger' were thought by staff and some of the young people to be ambiguous, being variously interpreted as a rediscovered hunger for life as well as for an enjoyment in eating healthy food or natural (physical) hunger in young adults. Some of the young people also interpreted the term 'weight change' in one narrative as highlighting existing eating disorders.

The stages, and the narratives associated with them, were further discussed and validated by the same process by the research team and service practitioners attending a two-day workshop conducted by the research team and held in Sydney in September 2010. The draft MJM/eMJM was then trialled among project research associates and with staff and young people at one residential centre in November 2010. The language and content of some narratives were further refined in response to feedback from the young people in these trial sessions. Training of staff from all centres in the administration of the final MJM/eMJM took place in Sydney and in Perth in late January 2011.

\section{Method of administration}

One staff member first enters demographic information into the eMJM or paper-based scoring sheet, without the young person present. Then, the young person is invited to read, or have read to them (dependent upon their literacy level), and to choose from a series of narratives. These relate initially to what we have called the 'key stage', establishing a 'big picture' view of where along the continuum of stages (shut down, resisting, awakening, dreaming, doing) the young person feels him or herself to be at that point in time. Next, the young person works through a separate set of five narratives, again reflecting the continuum of stages, within each of the five dimensions (social, emotional and psychological, physical, drug use and developmental) choosing the one narrative they most closely identify with within that dimension or, where none apply, taking the 'unable to choose' option. Two staff members then separately complete the same process, recording their views of where they believe the young person to be situated in terms of key stage and each dimension. 


\section{Trial implementation}

Collection of data using the MJM/eMJM began in February 2011, across four residential rehabilitation centres in Western Australia and in New South Wales, the two states in which project partners are located. Participating centres were provided with access to the electronic version of the instrument and with sets of the paper-based tool and scoring sheets. Three of the centres found the paper-based MJM better suited their needs: in two cases, staff found it to be simpler to use, and in the third case, this choice was primarily due to limited access to computing facilities in a private space. Data from the MJMs from these centres was later entered into the eMJM by the project manager. Only one centre entered data directly into the eMJM.

It was expected that data would be collected at three phases between February and December 2011, consisting of a client self-rating, and the independent ratings of two staff members, for each young person at entry to the service (T1), and again on exit (T2), and wherever possible a self-rating and a rating from one staff member at three months after exit (T3). Each 'choice' of narrative from all three raters at $\mathrm{T} 1, \mathrm{~T} 2$, and $\mathrm{T} 3$ where available, is converted into a score between 1 and 6 . These sets of data at three points in time are then used to establish the predictive validity of the approach, assessed using the correlations between the scores for each young person on entry and on exit, and on entry and three months after exit; and test re-test reliability using data from the two staff members' rating at the same point in time.

Some interruptions to data collection were experienced almost immediately, resulting in a shortfall in expected T1 data by end June. As a result, it was decided to extend each phase of data collection by two months. In total, we collected 92 T1 assessments, 32 T2 assessments, and 13 T3 assessments.

The quantitative data on what stage of progress the young person is at is converted into a pictorial representation of that stage and used to provide the young person with a visual depiction of where 
they have been, compared to where they are now. Anecdotally, this has been a useful tool in feedback and reflection. The young people who have participated in this project appear to enjoy the process of assessment using the MJM, volunteering comments such as: "It's good that the stories have come from other kids like us"; “...strange, but fun”; “...yeah, that was pretty fun to do"; "Never done anything like it before...I like it, it's really different and it's funny"; “That's really good to do; a good process. You can tell them [the researchers] that it works from what I can tell. I think it shows a good overall picture of me and how my life is at the moment". Some use the 'comment' space in the tool to expand on their 'tick box' answers and to describe how they are feeling physically and mentally, or to comment on the tool itself.

Both the young people and the staff recognised and gave examples of people they knew in various stages, and staff commented that the stages made sense to them and reminded them of young people in their care. On discharge from the services, some young people reacted with surprise and pleasure at the visible change to their MJM profiles:

Prior to completing exit assessment: "I think I scored myself about the same as the first time (I did it)" ... Following completion of exit assessments: "Wow. Yeah, I knew that l'd changed, but I didn't realise how much. That's really good to see".

“...it's good to actually see changes in different areas. It makes me feel good...I'm gonna get out there and work really hard".

Staff administering the MJM to the young people commented that it is an "easy to use tool", that the five stages make sense and are a good guide to follow, and that basic post-assessment comparisons of two staff ratings appear to show good inter-rater reliability. They note some concerns, however, around the difficulties of rating young people who have mental health issues or cognitive deficits, and around those aspects of the tool regarding attitudes to partners, sex, and 
nutrition. Staff have also flagged some difficulties both with capturing data from some of the young people on exit - for example, if they are discharged on a weekend when staff are unavailable to assess them, or leave the service unexpectedly - and, as already mentioned, at three month followup.

\section{Discussion and Conclusion}

This research aims to develop a qualitative approach that captures, at three points in time and from multiple viewpoints, the progress of the young people in the services across several dimensions of the personal and social aspects of life. In mapping change over time, the MJM allows for the often complex and non-linear nature of change, and provides an uncomplicated visual representation of the journey which appears to be empowering and motivating for the young people involved in the research. The MJM is easy to administer and the narratives, reflecting the 'voices' of their peers, are familiar and entertaining, considerably enhancing the possibilities of engaging the young people in charting and reflecting on their own progress through treatment.

There is a pressing need to optimise treatment in adolescents with problematic substance use and to obtain successful outcomes among this population. There has been growing awareness in recent years of the need to integrate domains of particular relevance to adolescence into the research methodology. Similarly, more adolescent-specific outcome measures are currently being developed and some adult-focused measures have been adapted for the adolescent population (see Deady, 2009). There is also a recognition that both studies of treatment programs and the development of outcome measures will benefit from the inclusion of the voices of the young people themselves (Bell, 2007; Colby et al., 2004).

Existing indicators of treatment experience and success include client engagement, client satisfaction, and change over time (see Reisinger, Bush, Colom, Agar, \& Battjes, 2003; Wilson et al., 
2008). Quantitative tools which measure retention, completion, and post-treatment abstinence risk overlooking the often recursive but nevertheless incremental gains made by young people within treatment which can lead to attitudinal change and harm reduction. The qualitative approach we are using in this project captures multiple perspectives, relying upon baseline self and staff assessments at entry to the service, contrasted with repeat assessments on exit from the service and, where possible, at three month follow up after exit. Data collected using the MJM approach can supplement quantitative data collected routinely by treatment services, to inform, illustrate, confirm or even challenge the interpretation of those data. The MJM approach is not tied to retention in the service or to completion of the program, but instead captures change over time, no matter how short, and progress during treatment across each aspect of the five dimensions.

There is a growing need to provide treatment services that can demonstrate success in outcomes for the young people in their care. Given the transitioning and developmental nature of adolescence and the multi-faceted issues with which many of these young people are struggling, such success is not necessarily obvious in absolute measures of retention or completion. Rather, for many of the young people in residential AOD rehabilitation, success can best be measured in the nuances of the developmental journey that they take through treatment. This research has the potential to contribute to the ability of residential rehabilitation services for young people with problematic drug and alcohol issues to record and celebrate incremental change. This may not result in abstinence or treatment completion, but may nevertheless reflect success and provide young people with impetus for further positive change across various aspects of their lives. 


\section{Acknowledgements}

The research team would like to thank all the staff and young people in the services who have participated in this project.

The authors would like to acknowledge the assistance of the wider research team, and associates past and present: Carmen Acosta, Malcolm Brunton, Rebecca Clair, Allan Colthart, Gillian Considine, Jagdish Dua, Sarah Green, Anne Hampshire, Joann Fildes, Charlie Laidlaw, Tim Marchant, Peta Nordberg, Ronan O'Connor, Tricia O'Riordan, Sitharthan Thiagarajan, Susie Thompson, Andrew Walden, Lisa Webb, and Sam Wilson. Joanne Faulkner translated the design into both a paper-based (MJM) and electronic (eMJM) practical tool.

This research was supported under Australian Research Council's Linkage Projects funding scheme (project number LP100100266). 


\section{BIBLIOGRAPHY}

American Association of Children's Residential Centers. (2009). Redefining residential: performance indicators and outcomes. Residential Treatment for Children \& Youth, 26(4), 241-245.

Australian Institute of Health and Welfare. (2005). National Comorbidity Initiative. A review of data collections relating to people with coexisting substance use and mental health disorders (AIHW cat. no. PHE 60). Canberra: Australian Institute of Health and Welfare.

Bell, E. (2007). Time, space and body in adolescent residential services: re-imagining service research. Addiction Research and Theory, 15(1), 97-111.

Boyd, A.S., Einbinder, S.D., Rauktis, M.E., \& Portwood, S.G. (2007). Building research capacity in residential treatment centers: an approach for empirical studies. Child \& Youth Care Forum, 36, 43-58.

Brown, Sandra A. (2004). Measuring youth outcomes from alcohol and drug treatment. Addiction, 99(Suppl. 2), 38-46.

Bukstein, O.G., \& Winters, K. (2004). Salient variables for treatment research of adolescent alcohol and other substance use disorders. Addictions, 99((Suppl. 2)), 23-37.

Butler, Linda S., Little, Liza, \& Grimard, Andre R. (2009). Research challenges: implementing standardized outcome measures in a decentralized, community-based residential treatment program. Child \& Youth Care Forum, 38(2), 75-90.

Chassin, Laurie, Knight, George, Vargas-Chanes, Delfino, Losoya, Sandra H., \& Naranjo, Diana. (2009). Substance use treatment outcomes in a sample of male serious juvenile offenders. Journal of Substance Abuse Treatment, 36(2), 183-194.

Chung, T., \& Maisto, S.A. (2009). "What I got from treatment": predictors of treatment content received and association of treatment content with 6-month outcomes in adolescents. Journal of Substance Abuse Treatment, 37, 171-181.

Colby, Suzanne M., Lee, Christina S., Lewis-Esquerre, Johanna, Esposito-Smythers, Christianne, \& Monti, Peter M. (2004). Adolescent alcohol misuse: methodological issues for enhancing treatment research. Addiction, 99(Suppl. 2), 47-62.

Collins, D.J., \& Lapsley, H.M. (2002). Counting the cost: estimates of the social costs of drug abuse in Australia 1998-9. NDS Monograph Series, No. 49. Canberra: AGPS.

Deady, Mark. (2009). A review of screening, assessment and outcome measures for drug and alcohol settings. Sydney, New South Wales: Network of Alcohol \& other Drug Agencies (NADA).

Delaney, P.J., Broome, K.M., Flynn, P.M., \& Fletcher, B.W. (2001). Treatment service patterns and organizational structures: an analysis of programs in DATOS-A. Journal of Adolescent Research, 16(6), 590-607.

Etheridge, Rose M., Smith, Jeff C., Rounds-Bryant, Jennifer L., \& Hubbard, Robert L. (2001). Drug abuse treatment and comprehensive services for adolescents. Journal of Adolescent Research, 16(6), 563-589.

Faw, Leyla, Hogue, Aaron, \& Liddle, Howard A. (2005). Multidimensional implementation evaluation of a residential treatment program for adolescent substance abuse. American Journal of Evaluation, 26, 77-94.

Flanzer, J. (2005). The status of health services research on adjudicated drug-abusing juveniles: selected questions and remaining questions. Substance Use \& Misuse, 40, 887-911.

Fletcher, Adam, Calafat, Amador, Pirona, Alessandro, \& Olszewski, Deborah. (2010). Young people, recreational drug use and harm reduction. In T. Rhodes \& D. Hedrich (Eds.), Harm reduction: evidence, impacts and challenges (pp. 357-376). Luxembourg: Publications Office of the European Union.

Ford II, James H., Green, Carla A., Hoffman, Kim A., Wisdom, Jennifer P., Riley, Katherine J., Bergmann, Luke, \& Molfenter, Todd. (2007). Process improvement needs in substance abuse treatment: admissions walk-through results. Journal of Substance Abuse Treatment, 33, 379389. 
Gray, D., \& Saggers, S. (2005). Preventing harmful substance use among Indigenous people. In T. Stockwell, P. Gruenewald, J. Toumbourou \& W. Loxley (Eds.), Preventing harmful substance use: the evidence base for policy and practice (pp. 383-393). Chichester: John Wiley \& Sons Ltd.

Hser, Y., Grella, C.E., Hubbard, R.L., Hsieh, S.C., Fletcher, B.W., Brown, B.S., \& Anglin, M.D. (2001). An evaluation of drug treatments for adolescents in four U.S. cities. Archives of General Psychiatry, 58(7), 689-695.

Joshi, V., Grella, C.E., \& Hser, Y.I. (2001). Drug use and treatment initiation patterns: differences by birth cohorts. Journal of Drug Issues, 31(4), 1039-1062.

Knudsen, Hannah K. (2009). Adolescent-only substance abuse treatment: availability and adoption of components of quality. Journal of Substance Abuse Treatment, 36(2), 195-204.

Loxley, W., Toumbourou, J., \& Stockwell, T. (2004). The prevention of substance use, risk and harm in Australia: a review of the evidence. Canberra: Department of Health and Ageing.

Marsden, John, Gossop, Michael, Stewart, Duncan, Best, David, Farrell, Michael, \& Strang, John. (1998). The Maudsley Addiction Profile. A brief instrument for treatment outcome research. Development and user manual. London: National Addiction Centre/Institute of Psychiatry.

National Health and Medical Research Council. (2007). National statement on ethical conduct in research involving humans. Canberra: National Health and Medical Research Council.

Prior, ., Sanson, A., Smart, D., \& Oberklaid, F. (2000). Research Report No. 4. Pathways from infancy to adolescence: Australian Temperament Project 1983-2000. Canberra: Australian Institute of Family Studies.

Prochaska, James O., DiClemente, C.C., \& Norcross, J.C. (1992). In search of how people change. Applications to addictive behaviors. American Psychologist, 47(9), 1102-1114.

Reisinger, Heather Schacht, Bush, Trevor, Colom, M. Alejandra, Agar, Michael, \& Battjes, Robert. (2003). Navigation and engagement: how does one measure success? Journal of Drug Issues, 33(4), 777-800.

Rounds-Bryant, J.L., Kristiansen, P.L., Fairbank, J.A., \& Hubbard, R.L. (1998). Substance use, mental disorders, abuse, and crime: gender comparisons among a national sample of adolescent drug treatment clients. Journal of Child \& Adolescent Substance Use, 7(4), 19-34.

SAMHSA. (2004). Results from the 2004 National Survey on Drug Use and Health: national findings. US: Substance Abuse and Mental Health Services Administration.

Staiger, Petra K., Melville, Fritha, Hides, Leanne, Kambouropoulos, Nicolas, \& Lubman, Dan I. (2009). Can emotion-focused coping help explain the link between posttraumatic stress disorder severity and triggers for substance use in young adults? Journal of Substance Abuse Treatment, 36(2), 220-226.

Szirom, Tricia, King, Debbie, \& Desmond, Kathy. (2004). Barriers to service provision for young people with presenting substance misuse and mental health problems. Canberra: Australian Government Department of Family and Community Services on behalf of NYARS.

Toumbourou, John W., Hamilton, M., \& Fallon, B. (1998). Treatment level progress and time spent in treatment in the prediction of outcomes following drug-free therapeutic community treatment. Addiction, 93(7), 1051-1064.

Wagner, E.F. (2008). Developmentally informed research on the effectiveness of clinical trials: a primer for assessing how developmental issues may influence treatment responses among adolescents with alcohol use problems. Pediatrics, 121, S337-S347.

Wagner, E.F. (2009). Improving treatment through research: directing attention to the role of development in adolescent treatment success. Alcohol Research \& Health, 32(1), 67-75.

Williams, R.J., \& Chang, S.Y. (2000). A comprehensive and comparative review of adolescent substance abuse treatment outcome. Clinical Psychology: Science and Practice, 7(2), 138166. 
Wilson, Mandy, Saggers, Sherry, \& Wildy, Helen. (2008). Outcome measures for young people attending substance misuse services for detoxification and residential rehabilitation in Perth, Western Australia. Perth: Centre for Social Research, Edith Cowan University.

Winters, K., Stinchfield, R., Latimer, W., \& Lee, S. (2007). Long-term outcome of substancedependent youth following 12-step treatment. Journal of Substance Abuse Treatment, 33, 61-69.

Winters, Ken C. (1992). Development of an adolescent alcohol and other drug abuse screening scale: personal experience screening questionnaire. Addictive Behaviors, 17, 479-490. 